\section{Intercropping Cabbage and Indian Mustard for Potential Control of Lepidopterous and Other Insects}

\author{
David A. Bender \\ Texas A\&M Agricultural Research and Extension Center, Rt. 3, Box 219, \\ Lubbock, TX 79401-9757

\section{William P. Morrison and Raymond E. Frisbie \\ Department of Entomology, Texas A\&M University, College Station, TX 77843-2475}

Additional index words. Brassica oleracea, Brassica juncea, diamondback moth, cabbage looper, harlequin bug, integrated pest management

\begin{abstract}
A system of intercropping cabbage (Brassica oleracea var. capitata L.) with Indian mustard [Brassica juncea (L.) Czern.] to reduce pesticide applications was evaluated over three cropping seasons. Insects were monitored in nonintercropped cabbage, cabbage plots surrounded by Indian mustard, and the Indian mustard intercrop. Insecticide applications were made to individual plots based on specific treatment thresholds for lepidopterous insects and accepted pest management practices for other insects. Intercropping had no significant effect on the number of lepidopterous larvae in cabbage. Indian mustard did not appear to preferentially attract lepidopterous insects, but was highly attractive to hemipterans, especially harlequin bugs [Murgantia histrionica (Hahn)]. In one season with heavy harlequin bug pressure, intercropping with Indian mustard eliminated two insecticide applications to cabbage. Intercropping cabbage with Indian mustard does not appear to be an economical pest management practice under normal pest pressures in West Texas.
\end{abstract}

Diamondback moth [Plutella xylostella (L.)] (DBM) is a major insect pest of cabbage and other crucifers worldwide. Resistance of DBM to all major classes of insecticides (Cheng, 1986; Myata et al., 1986; Shelton and Wyman, 1992; Sun et al., 1986) and to some biologicals (Tabashnik et al., 1990) has been reported, making DBMs an increasingly significant component of the crucifer pest complex. Since the mid-1980s DBM has emerged as a major threat to cabbage production in the southwestern United States (Magaro and Edelson, 1990), at times causing loss of entire fields. An integrated program combining aggressive sanitation practices, alternation of classes of insecticides, and inclusion of Bacillus thuringiensis $(B t)$ materials in every insecticide application has provided economically acceptable control (Talekar and Shelton, 1993). However, the long-term success of this approach is uncertain, and alternative control strategies that reduce pesticide use are needed.

Interplanting cruciferous crops with various companion species to reduce lepidopterous pest pressure has met with varying levels

Received for publication 3 Feb. 1998. Accepted for publication 13 July 1998. This research was partially funded by ES-USDA Grant 91-EPMP-1-0005. We thank Ed Riley, Dept. of Entomology, Texas A\&M Univ., for the identification of insects in this study, and Don Douglas and John Baker for technical assistance. The cost of publishing this paper was defrayed in part by the payment of page charges. Under postal regulations, this paper therefore must be hereby marked advertisement solely to indicate this fact. of success (Buranday and Raros, 1975; Latheef and Irwin, 1979; Latheef and Ortiz, 1983). Buranday and Raros (1975) reported that interplanting cabbage and tomatoes (Lycopersicon esculentum Mill.) reduced DBM damage to cabbage. Talekar et al. (1986) intercropped cabbage in Taiwan with 54 different crops for control of DBM. Tomato, dill (Anethium graveolens L.), safflower (Carthamus tinctorius $\mathrm{L}$.), garlic (Allium sativum L.), oat (Avena sativa L.), and barley (Hordeum vulgare L.) reduced DBM damage to cabbage. Mustard was included in the study, but was not one of the species reported to be effective for intercropping.

Srinivasan and Krishna Moorthy (1991) reported that Indian mustard was favored over cabbage as an oviposition host for DBM. CabIndia, had significantly higher larval populations than did cabbage intercropped with Indian mustard. Mustard rows were seeded between each 15 rows of cabbage and sprayed at 10-d intervals to control insects. In three tests, two cabbage crops were successfully grown bage grown alone in field tests at Bangalore, with no insecticide, and the third required only two applications. Later studies indicated that paired mustard rows at either end of 25 cabbage rows was the most effective planting pattern for successful DBM management (Srinivasan and Krishna Moorthy, 1992).

Insects can attack cabbage soon after emergence, making it necessary to seed the mustard $15 \mathrm{~d}$ before seeding the cabbage to ensure adequate trap crop foliage. Indian mustard also completes vegetative growth and flowers $\approx 40 \mathrm{~d}$ after seeding, after which it becomes less attractive to DBM. Succession plantings of Indian mustard in paired rows were necessary to maintain an effective trap crop (Srinivasan and Krishna Moorthy, 1991).

Luther et al. (1996) evaluated a similar intercropping system in Hawaii. In their studies, numbers of DBM larvae in cabbage intercropped with Indian mustard were equal to or greater than those in cabbage planted alone. Other lepidopterous pests were preferentially attracted to Indian mustard or a highly susceptible cabbage cultivar used as trap crops. The potential for using a similar intercropping system for controlling lepidopterous crucifer pests in other areas has not been determined. In 1992 a study was initiated to evaluate a cabbage-Indian mustard intercrop system under Texas High Plains growing conditions.

\section{Methods and Materials}

Culture. Trap crop research plots were established in late Spring and Fall 1992 and late Spring 1993 on an Acuff loam (fineloamy, mixed-thermic, Aridic Paleustoll) at the Texas A\&M Agricultural Research and Extension Center, Lubbock, Texas (Table 1). Irrigation based on tensiometer readings of $>25 \mathrm{kPa}$ was applied through a drip system. Preplant fertilization with $\mathrm{N}\left(90 \mathrm{~kg} \cdot \mathrm{ha}^{-1}\right)$ and $\mathrm{P}$ (112 $\mathrm{kg} \cdot \mathrm{ha}^{-1}$ ) was supplemented by two sidedress applications of $\mathrm{N}\left(20 \mathrm{~kg} \cdot \mathrm{ha}^{-1}\right)$ through the irrigation system.

Oilseed-type Indian mustard seed was obtained from Dr. K. Srinivasan, Indian Institute of Horticultural Research, Bangalore, India, and increased in 1991 by Dr. Robert Cartwright, Oklahoma State Univ. Mustard was seeded at $3-5 \mathrm{~cm}$ spacing in one of two border rows of each protected plot and the end border area of two of the three cabbage rows (Fig. 1) 15-25 $\mathrm{d}$ before seeding of cabbage in the spring and $8 \mathrm{~d}$ before seeding in midsummer (Table 1). When Indian mustard from the first seeding bolted, the second seeding was made in the remaining border areas. Plants from the first seeding were removed before seed pods dried sufficiently to begin shattering. A third seed-

Table 1. Planting and harvest dates for interplanting studies with cabbage and mustard.

\begin{tabular}{|c|c|c|c|c|c|}
\hline \multirow[b]{3}{*}{ Crop } & \multicolumn{4}{|c|}{ Seeding dates } & \multirow[b]{3}{*}{ Harvest dates } \\
\hline & \multicolumn{3}{|c|}{ Mustard } & \multirow[b]{2}{*}{ Cabbage } & \\
\hline & First & Second & Third & & \\
\hline Spring 1992 & 22 Apr. & 8 June & & 8 May & $\begin{array}{l}11 \text { Aug. } \\
25 \text { Aug. }\end{array}$ \\
\hline Fall 1992 & 28 July & 4 Sept. & & 5 Aug. & 28 Nov. \\
\hline Spring 1993 & 27 Apr. & 2 June & 17 June & 20 May & $\begin{array}{l}3 \text { Sept. } \\
16 \text { Sept. }\end{array}$ \\
\hline
\end{tabular}


ing was made in 1993, when mustard plants from the first seeding were removed to ensure that protected plots were surrounded by nonflowering Indian mustard throughout the cabbage growing season.

Experimental design. Plots were arranged in a randomized complete-block design with four replications. Intercropped cabbage plots (IN) $9.2 \mathrm{~m} \times 3.1 \mathrm{~m}$ in size, comprised of three single rows of 'Bravo' cabbage spaced $0.3 \mathrm{~m}$ within rows and $1.0 \mathrm{~m}$ between rows, were bordered by two rows of Indian mustard on the sides and by $1.8 \mathrm{~m}$ at the end of plots. Nonintercropped cabbage plots (NIN) were planted in the same configuration but physically isolated from Indian mustard by a minimum of $10 \mathrm{~m}$.

Insect monitoring. Counts of all insects found on five center-row cabbage and five Indian mustard plants in each plot were made at 3- to 7-d intervals depending on insect pressure. Lepidopterous larvae were classified as small, medium, or large, and eggs, pupae, and adults were counted where practical. Numbers of beneficial insects were also recorded.

Insecticide applications. Insecticides were applied to individual cabbage plots when composite numbers of lepidopterous larvae exceeded 0.5 per plant pre-cupping or 0.3 per plant post-cupping (Cartwright et al., 1987; Kirby and Slosser, 1984) (Table 2). Other insects were controlled when total numbers or rate of population increase threatened survival of the Indian mustard or yield and marketability of the cabbage. The primary objective of the insect management practices in this study was to protect cabbage marketability with minimal impact on beneficial insects and minimal use of nonbiological pesticides. Thus, biological insecticides were primarily used to control lepidopterous larvae, and short residual insecticides were used when necessary for other phytophagous insects. Insecticides

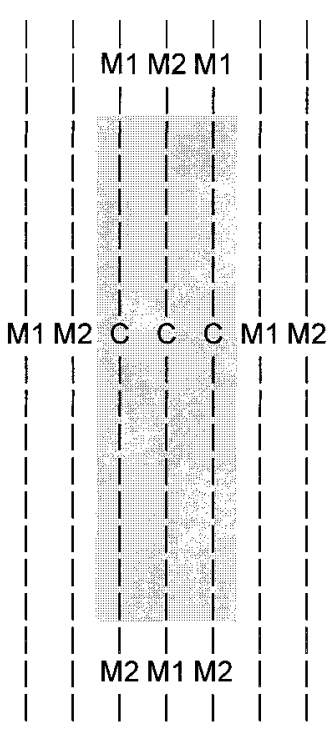

Fig.1. Layout of representative Indian mustardcabbage intercrop plot. $\mathrm{C}=$ cabbage; $\mathrm{M} 1=$ Indian mustard, first seeding; M2 = Indian mustard, second seeding. with higher toxicity or longer residual were used only when the aforementioned treatments failed to maintain insect numbers below acceptable levels. In several cases, protection of the Indian mustard with insecticide applications was necessary even when the cabbage was not infested.

\section{Results}

Spring 1992. Three early-season carbaryl [1-napthalenyl methylcarbamate] applications were required to control western black flea beetles (Phyllotreta pusilla Horn) on emerging Indian mustard seedlings, with cabbage transplants requiring two applications (Table 2). In early June, a few harlequin bugs were observed on the Indian mustard (Fig. 2). Over one weekend (5-8 June), immigration increased adult harlequin bug numbers to 24 per plant in the Indian mustard. Three carbaryl applications were needed to control the adults and the nymphs that emerged from egg masses deposited on the plants. A subsequent generation in mid-July necessitated two additional carbaryl applications to Indian mustard and NIN cabbage.

Adult harlequin bugs were highly attracted to Indian mustard, especially flowering plants, but adjacent cabbage plants had very few of the insects even though the mustard was heavily infested. No insecticide applications were required to control harlequin bugs on IN cabbage, but economically significant numbers of the bugs on NIN cabbage necessitated one carbaryl application.

A large migration of false chinch bugs (Nysius raphanus Howard) into the plots oc- curred in mid-July, coinciding with the appearance of second-generation harlequin bugs. These insects were also highly attracted to Indian mustard, and were so numerous as to threaten survival of the intercrop. The last carbaryl application for control of harlequin bugs also controlled the false chinch bugs, and no further economic infestations of these two pests occurred.

The lepidopterous insect complex was composed primarily of DBM and cabbage loopers [Trichoplusia ni (Hubner)], although a few southern cabbageworms [Pontia protodice (Boisduval and LeConte)] and imported cabbageworms [Pieris rapae (L.)] were present (Fig. 3). Larvae of DBM appeared in both IN and NIN cabbage in early June and numbers increased rapidly in mid-June. Cabbage loopers appeared about the same time, but did not reach economic levels until early July. An initial Bt (Javelin, Sandoz Crop Protection Corp., Des Plaines, Ill.) application on 23 June reduced lepidopterous larvae numbers below the treatment threshold, but populations quickly recovered as cabbage looper numbers increased. A second $B t$ application on 2 July failed to lower larval numbers below the threshold, necessitating an esfenvalerate [ $(S)$-cyano(3-phenoxyphenyl)methyl-( $S)$-4 chloroalpha-(1-methylethyl) benzene acetate] application to cabbage plots on 10 July. This treatment was effective, and no further insecticide applications were necessary until 28 July, when a gradual buildup raised larval numbers above the treatment threshold. Esfenvalerate was again effective in controlling both principal species.

Indian mustard did not appear to be more

Table 2. Insecticide applications to intercropped cabbage and Indian mustard in three growing seasons.

\begin{tabular}{|c|c|c|c|c|}
\hline Insecticide & $\begin{array}{c}\text { Rate } \\
\left(\mathrm{kg} \cdot \mathrm{ha}^{-1}, \text { a.i. }\right)\end{array}$ & Target insect & Date & Crop $^{z}$ \\
\hline & & Spring 1992 & & \\
\hline \multirow[t]{5}{*}{ Carbaryl } & 1.12 & Flea beetles & 7 May & M \\
\hline & & & 29 May, 8 June & M, IN, NIN \\
\hline & & Harlequin bugs & 11 June & NIN \\
\hline & & & 15 June & M, NIN \\
\hline & & & 23 June & $\mathrm{NIN}^{\mathrm{y}}$ \\
\hline$B t$ & 1.68 & Lepidopterous larvae & 23 June, 2 July & IN, NIN \\
\hline Esfenvalerate & 0.06 & & 10 July & IN, NIN \\
\hline Carbaryl & 1.12 & Harlequin bugs ${ }^{x}$ & 15 July, 20 July & $\mathrm{M}, \mathrm{NIN}^{\mathrm{w}}$ \\
\hline \multirow[t]{2}{*}{ Esfenvalerate } & 0.06 & Lepidopterous larvae & 28 July & IN, NIN \\
\hline & & Fall 1992 & & \\
\hline Dimethoate & 0.45 & Turnip aphid & 21 Aug., 25 Aug. & M, IN, NIN \\
\hline \multirow[t]{2}{*}{$B t$} & 1.68 & Lepidopterous larvae & 19 Sept., 14 Oct. & IN, NIN \\
\hline & & Spring 1993 & & \\
\hline \multirow[t]{5}{*}{ Carbaryl } & 1.12 & Flea beetles & 25 May, 14 June & M \\
\hline & & & 2 June & M, IN, NIN \\
\hline & & & 25 June & NIN \\
\hline & & Harlequin bugs & 21 June & M \\
\hline & & & 23 June & IN, NIN \\
\hline \multirow[t]{3}{*}{ Esfenvalerate } & 0.06 & Lepidopterous larvae & 6 July & $\mathrm{IN}^{\mathrm{v}}, \mathrm{NIN}^{\mathrm{y}}$ \\
\hline & & & 16 July & IN \\
\hline & & & 22 July & IN, NIN \\
\hline \multirow[t]{2}{*}{ Bt } & 1.68 & Lepidopterous larvae & 3 Aug. & IN, NIN \\
\hline & & & 19 Aug. & $\mathrm{NIN}^{\mathrm{y}}$ \\
\hline
\end{tabular}

${ }^{\mathrm{z}} \mathrm{M}=$ Indian mustard; IN = intercropped cabbage; $\mathrm{NIN}=$ nonintercropped cabbage.

${ }^{\mathrm{y}} 1$ of 4 replicates treated.

$\times 2$ of 4 replicates treated.

w3 of 4 replicates treated.

vDamaging numbers of false chinch bugs also present in Indian mustard on 20 July. 

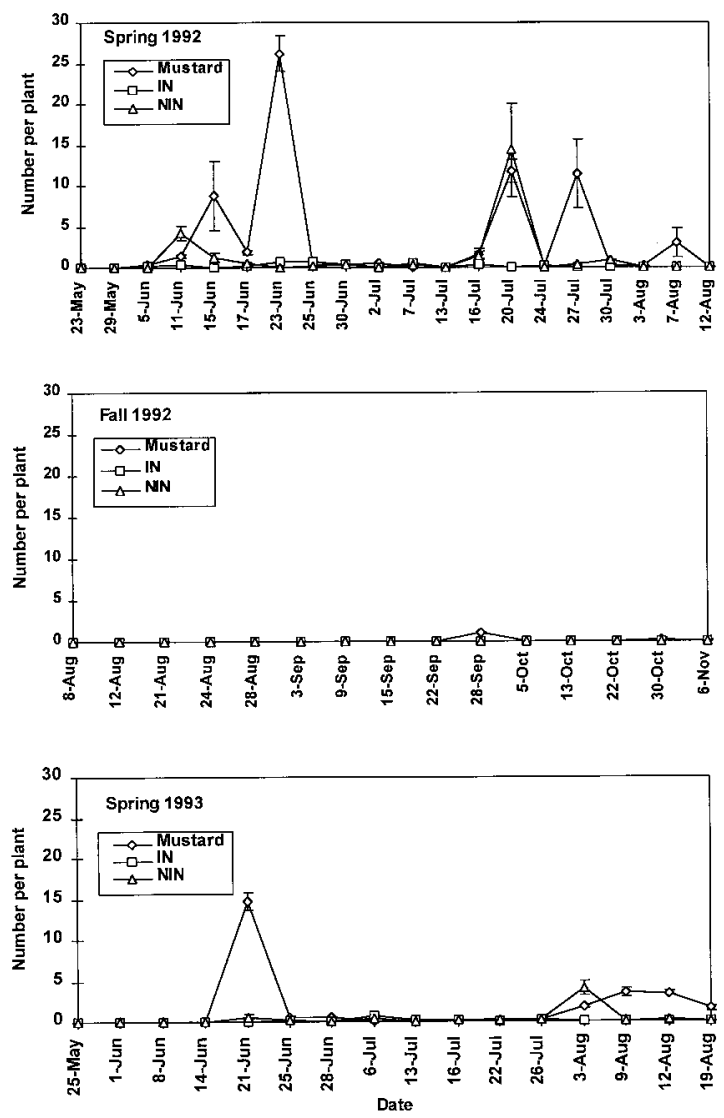

Fig. 2. Effect of intercropping with Indian mustard on mean number $( \pm \mathrm{sE}, \mathrm{n}=4)$ of harlequin bugs on cabbage plants in three growing seasons. IN-Intercropped cabbage; NIN-Nonintercropped cabbage. Data on Indian mustard included for comparison.
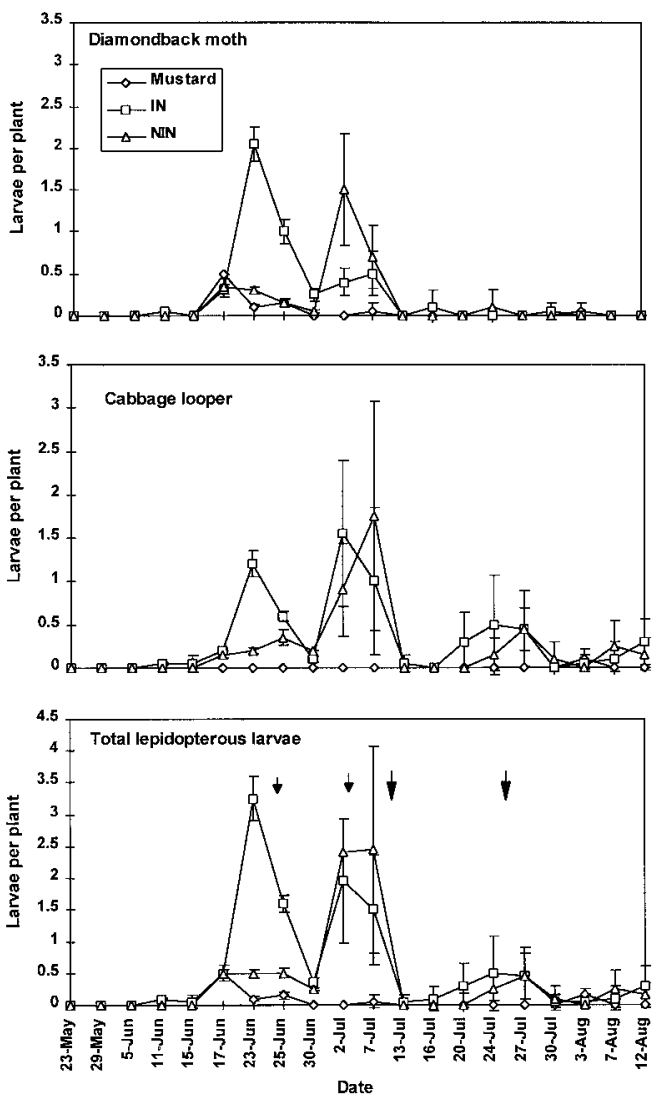

Fig. 3. Effect of intercropping with Indian mustard on mean number $( \pm \mathrm{sE}, \mathrm{n}=4)$ of lepidopterous larvae on cabbage plants in Spring 1992. IN-Intercropped cabbage; NIN-Nonintercropped cabbage. Data on Indian mustard included for comparison. attractive than cabbage to either DBM or imported cabbageworm. Variations among plots in larval numbers of each lepidopterous species resulted in statistically different populations between IN and NIN cabbage at individual dates (Fig. 3). However, no clear preference pattern was evident across the growing season. Larval numbers in the trap crop were very low throughout the season, and were almost always lower than in adjacent cabbage. No insecticide applications were required to control lepidopterous larvae in Indian mustard.

No significant differences in cabbage marketable yields or head weight were detected between IN and NIN plots. Yields averaged $29.8 \mathrm{t} \cdot \mathrm{ha}^{-1}$ and head weights $1.45 \mathrm{~kg}$. Insect feeding damage to the heads was minimal and confined to the outer wrapper leaves. No larvae were present in the heads at harvest. Quality and cull rates $(<1 \%)$ were similar for both treatments.

Fall 1992. Cabbage and Indian mustard emerging in early August had no economically important insect infestations until a mass migration of alate turnip aphids [Liphaphis erysimi (Kaltenbach)] occurred on 21 Aug. Aphid numbers exceeded 95 per plant on the Indian mustard and 25 per plant on the smaller cabbage plants. Two applications of dimethoate $\{O, O$-dimethyl S-[2-(methylamino)-2oxoethyl] phosphorodithioate $\}$ were required to reduce populations to acceptable levels (Table 2). Flea beetles and harlequin bugs appeared in the Indian mustard in late September, but did not become economically significant. Western flower thrips [Frankliniella occidentalis (Pergande)] were very numerous in cabbage during the last half of the growing period, but remained primarily on the oldest leaves and did not affect head size or quality. Lepidopterous larval numbers were lower than in the spring crop (Fig. 4). Southern cabbageworm approached the treatment threshold on Indian mustard in mid-August and again in mid-September, but were not found on the cabbage plants. Cabbage loopers were present in low numbers during September and October, primarily on cabbage. Larvae of DBM also appeared on cabbage in early September, and increased to high populations in early October. Very few DBM were found on Indian mustard. Two applications of $B t$ were adequate to control the lepidopterous larvae complex in the fall crop. Yield $\left(31.4 \mathrm{t} \cdot \mathrm{ha}^{-1}\right)$ and head weight $(1.08 \mathrm{~kg})$ were not significantly affected by intercropping with Indian mustard.

Spring 1993. Flea beetles attacked both seedling Indian mustard and cabbage soon after emergence, and carbaryl applications were required to protect small plants (Table 2). Although western flower thrips increased rapidly in the Indian mustard in early June, they declined to very low levels by the end of the month and did not require an insecticide application. Significant numbers of harlequin bugs appeared in Indian mustard in mid-June (Fig. 2 ), but were controlled by two carbaryl applications and did not require further treatment. Aphid populations rose to relatively high lev- 

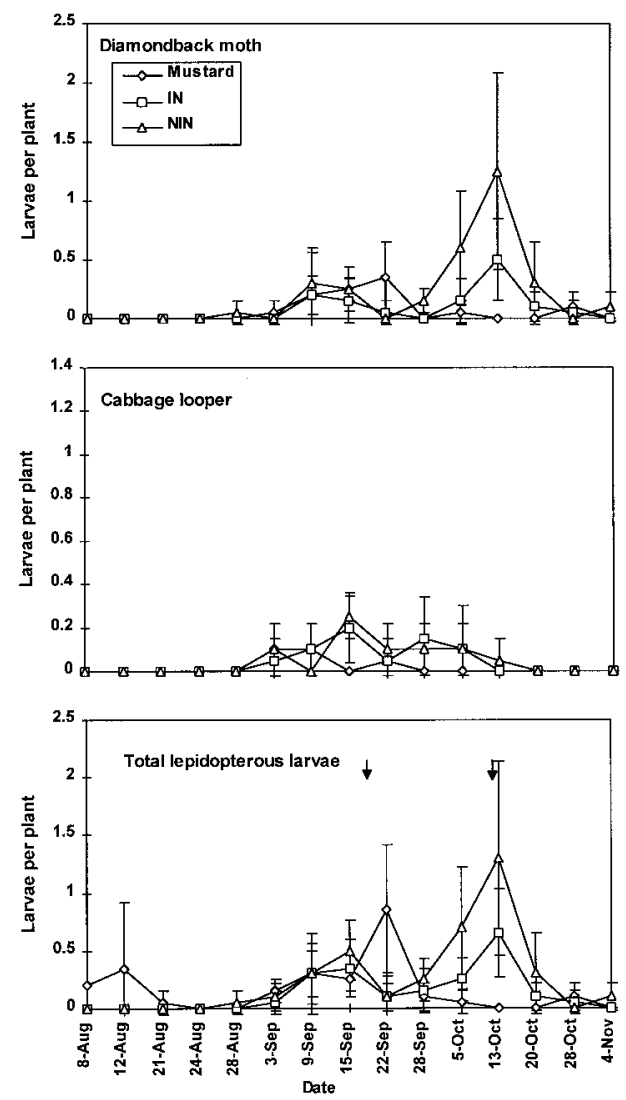

Fig. 4. Effect of intercropping with Indian mustard on mean number $( \pm s E, n=4)$ of lepidopterous larvae on cabbage plants in Fall 1992. IN-Intercropped cabbage; NIN-Nonintercropped cabbage. Data on Indian mustard included for comparison.
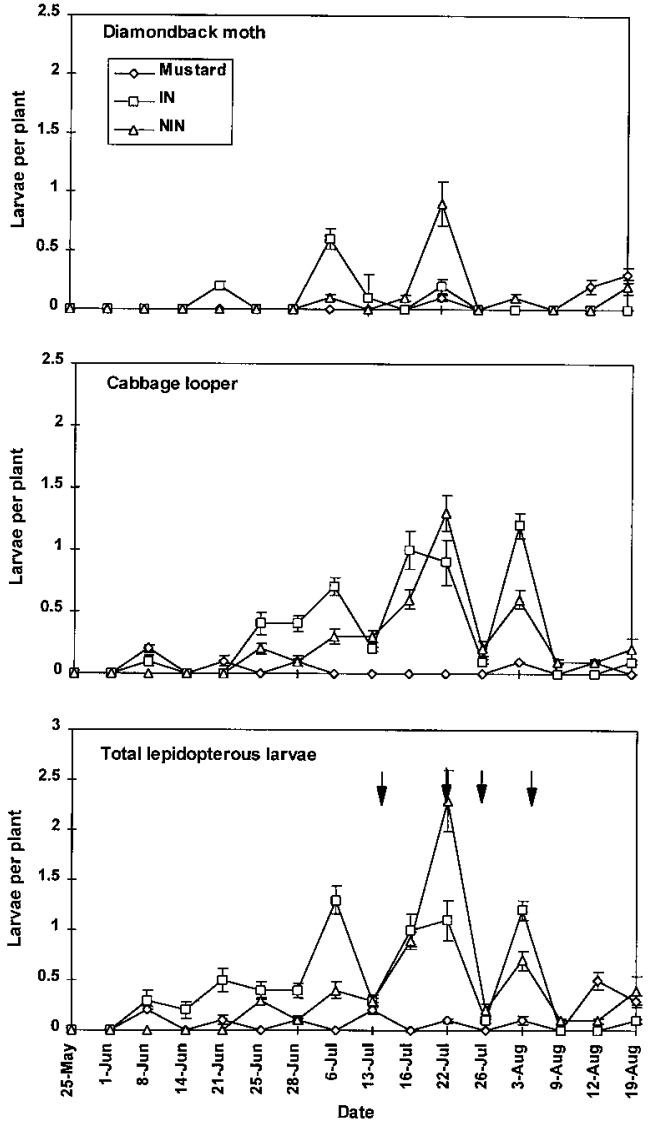

Fig. 5. Effect of intercropping with Indian mustard on mean number $( \pm \mathrm{SE}, \mathrm{n}=4)$ of lepidopterous larvae on cabbage plants in Spring 1993. IN-Intercropped cabbage; NIN-Nonintercropped cabbage. Data on Indian mustard included for comparison. els in late June and early July, then declined rapidly because of high day temperatures and increased predator and parasite activity.

Lepidopterous larvae, primarily DBM and cabbage loopers, reached economic levels in cabbage plots in early June (Fig. 5). Although several pesticide applications ( $B t$ and esfenvalerate) were made to individual plots during July and August, average populations remained at or above treatment thresholds for most of the growing period. As in 1992, few lepidopterous larvae were found on the Indian mustard, and the presence or absence of the companion crop did not consistently influence larval numbers in cabbage plots. As in previous trials, marketable yield and cabbage head weight were not significantly affected by the intercropping treatments.

\section{Discussion}

Contrary to previous reports from India, oilseed Indian mustard did not appear to be more attractive than cabbage to any lepidopterous pests present in these studies. Numbers of larvae were consistently higher in cabbage plots than in the companion crop, and no consistent differences were found between populations in IN and NIN cabbage plots. This supports the results of Luther et al. (1996) in Hawaii, who found that Indian mustard was not preferentially attractive to DBM. A. Loughton and R. Baker, Horticultural Institute of Ontario, Simcoe, Ont. (personal communication), reported a similar lack of preference using Chinese cabbage (Brassica rapa L. Pekinensis group) or Indian mustard as a companion crop to cabbage or brussels sprouts (Brassica oleracea L. Gemmifera group) in Ontario. Loughton suggested possible preference differences among DBM populations, a view supported by D. Bigger, Univ. of California-Santa Cruz (personal communication). The lack of preference for Indian mustard exhibited by the lepidopterous species studied in this trial limited the value of intercropping to control of hemipterous insects. Harlequin bugs are the only significant hemipterous pests of commercial cabbage in the Southwestern United States. If detected early, they are easily controlled with insecticide in the first generation and usually do not pose a serious threat to the crop thereafter. An Indian mustard intercrop probably would not be a cost-effective insect management practice for cabbage production in the Texas High Plains.

\section{Literature Cited}

Buranday, R.P. and R.S. Raros. 1975. Effects of cabbage-tomato intercropping on the incidence and oviposition of the diamondback moth (Plutellaxylostella (L.). Philipp. Ent. 2:369-374.

Cartwright, B., J.V. Edelson, and C. Chambers. 1987. Composite action thresholds for the control of lepidopterous pests on fresh-market cabbage in the Lower Rio Grande Valley. J. Econ. Entomol. 80:175-181.

Cheng, E.Y. 1986. The resistance, cross resistance and chemical control of diamondback moth in Taiwan, p. 329-345. In: N.S. Talekar (ed.). Diamondback moth management. Asian Veg. 
Res. Dev. Ctr. Pub. 86-248, Shanhua, Taiwan.

Kirby, R.D. and J.E. Slosser. 1984. Composite economic threshold for three lepidopterous pests of cabbage. J. Econ. Entomol. 77:725-733.

Latheef, M.A. and R.D. Irwin. 1979. The effect of companionate planting on lepidopteran pests of cabbage. Can. Entomol. 111:63-864.

Latheef, M.A. and J.H. Ortiz. 1983. Influence of companion plants on oviposition of imported cabbageworm, Pieris rapae (Lepidoptera: Pieridae), and cabbage looper, Trichoplusa ni (Lepidoptera: Noctuidae), on collard plants. Can. Entomol. 115:1529-1531.

Luther, G.C., H.R. Valenzuela, and J. DeFrank. 1996. Impact of cruciferous trap crops on lepidopteran pests of cabbage in Hawaii. Environ. Entomol. 25:39-47.

Magaro, J.J. and J.V. Edelson. 1990. Diamondback moth (Lepidoptera: Plutellidae) in South Texas: A technique for resistance monitoring in the field. J. Econ. Entomol. 83:1201-1206.
Myata, T., T. Saito, and V. Noppun. 1986. Studies on the mechanism of diamondback moth resistance to insecticides, p. 347-357. In: N.S. Talekar (ed.). Diamondback moth management. Asian Veg. Res. Dev. Ctr. Pub. 86-248, Shanhua, Taiwan.

Shelton, A.M. and J.A. Wyman. 1992. Insecticide resistance of diamondback moth in North America, p. 447-454. In: N.S. Talekar (ed.). Diamondback moth and other crucifer pests. Asian Veg. Res. Dev. Ctr. Pub. 92-368, Shanhua, Taiwan.

Srinivasan, K. and P.N. Krishna Moorthy. 1991. Indian mustard as a trap crop for management of major lepidopterous pests on cabbage. Trop. Pest Mgt. 37:26-32.

Srinivasan, K. and P.N. Krishna Moorthy. 1992. Development and adoption of integrated pest management for major pests of cabbage using Indian mustard as a trap crop, p. 511-521. In: N.S. Talekar(ed.). Diamondback moth and other crucifer pests. Asian Veg. Res. Dev. Ctr. Pub. 92-368, Shanhua, Taiwan.

Sun, C.N., T.K. Wu, J.S. Chen, and W.T. Lee. 1986. Insecticide resistance in diamondback moth, $\mathrm{p}$. 359-371. In: N.S. Talekar (ed.). Diamondback moth management. Asian Veg. Res. Dev. Ctr. Pub. 86-248, Shanhua, Taiwan.

Tabashnik, B.E., N.L. Cushing, N. Finson, and M.W. Johnson. 1990. Field development of resistance to Bacillus thuringiensis in diamondback moth (Lepidoptera: Plutellidae). J. Econ. Entomol. 80:1091-1099.

Talekar, N.S., S.T. Lee, and S.W. Huang. 1986. Intercropping and modification of irrigation method for the control of diamondback moth, $p$. 145-151. In: N.S. Talekar (ed.). Diamondback moth management. Asian Veg. Res. Dev. Ctr. Pub. 86-248, Shanhua, Taiwan.

Talekar, N.S. and A.M. Shelton. 1993. Biology, ecology and management of the diamondback moth. Annu. Rev. Entomol. 38:275-301. 